\title{
Variation of Hydroxychloroquine Blood Levels in Moroccan Patients with Systemic Lupus Erythematosus; A Pilot Study
}

Naoual El Omri ${ }^{1 *}$, Fadwa Mekouar ${ }^{1}$, Naoufal Assoufi ${ }^{1}$, Abdelkhalek Maaroufi ${ }^{1}$, Amal Charef ${ }^{1}$, Jihane Smaali ${ }^{1}$, Mohamed $\mathrm{Jira}^{1}$, Jamal Fatihi ${ }^{1}$ and Rachid Eljaoudi ${ }^{2,3}$

${ }^{1}$ Internal Medicine Department, Military Teaching Hospital Mohammed V, Rabat, Morocco

${ }^{2}$ Pharmacology and Toxicology Department, Faculty of Medicine and Pharmacy, University Mohammed V, Rabat, Morocco

${ }^{3}$ Medical Biotechnology Lab (MedBiotech), Faculty of Medicine and Pharmacy, University Mohammed V, Rabat, Morocco

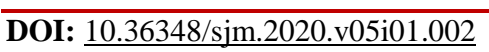

| Received: 27.12.2019 | Accepted: 04.01.2020 | Published: 11.01.2020
\end{abstract}

*Corresponding author: Naoual El Omri

\section{Abstract}

Aim of the study: The aim was to determine the blood concentrations of hydroxychloroquine in Moroccan systemic lupus erythematosus patients and identify the factors associated with interindividual variation. Methods: A cross-sectional study enrolled patients with lupus erythematosus. We recorded demographic features of patients and main clinical and biological characteristics of the disease. We determined the blood concentrations of hydroxychloroquine for the entire patient enrolled in this study by liquid chromatography - mass spectrometry. Patients were divided according to their blood hydroxychloroquine level into three groups: low blood concentration $(<500 \mathrm{ng} / \mathrm{mL})$, therapeutic range $(500-2000$ $\mathrm{ng} / \mathrm{mL}$ ) and high blood HCQ concentration (>2000). Results: Eighty subjects were included; 77 were female and the mean age was $36.9 \pm 12,2$ years. The median concentration of hydroxychloroquine was $830 \mathrm{ng} / \mathrm{mL}$ (range: $35-3,200$ $\mathrm{ng} / \mathrm{mL}) ; 13$ patients $(16 \%)$ had low blood levels, $59(74 \%)$ were in therapeutic range while 8 (10\%) had high blood concentrations. Low body mass index and the use of corticosteroids were associated with high hydroxychloroquine concentrations ( $\mathrm{p}=0.03$ and $\mathrm{p}=0.02$ respectively). Conclusion: We report for the first time the blood concentration of hydroxychloroquine in Moroccan lupus patients and we found significant variability between patients for the same dose. Various factors affected this concentration and further studies are needed to expand the sample.

Keywords: Systemic lupus erythematosus, Hydroxychloroquine, Whole blood, Interindividual variation, Liquid chromatography, Tandem mass spectrometry.

Copyright @ 2020: This is an open-access article distributed under the terms of the Creative Commons Attribution license which permits unrestricted use, distribution, and reproduction in any medium for non-commercial use (NonCommercial, or CC-BY-NC) provided the original author and source are credited.

\section{INTRODUCTION}

Systemic lupus erythematosus (SLE) is a chronic inflammatory and autoimmune disease occurring preferentially in women (more than 90\%) and frequently starting at childbearing age. SLE can affect almost any organ system but the most frequently symptoms are cutaneous, articular, haematological and visceral [1]. Several drugs can be used for the treatment of SLE like corticosteroids, immunosuppressive agents, biological agents; but, hydroxychloroquine (HCQ) is considered as an essential therapeutic element in SLE. Indeed, this non expensive drug can prevent flares, thrombotic events, diabetes mellitus and dyslipidemia [2-5].

The usual dose of HCQ is $400 \mathrm{mg}$ daily in one or two divided doses. This drug appears to be relatively safe; common side effects include headaches, dizziness, gastrointestinal upset and rash. However, HCQ may have serious side effects such as retinopathy that imposes regular ophthalmologic monitoring for patients on long term therapy [6].

Blood concentrations of HCQ vary widely among patients with SLE, but little is known about factors that influence this blood concentration variability. Monitoring of HCQ blood concentrations in chronically treated patients helps clinicians in identifying adherence to treatment. A pharmacokinetic/pharmacodynamic relationship has been found in different situations, and a very low blood concentration of HCQ is a simple marker of nonadherence to treatment. This monitoring has been shown to contribute to predicting HCQ treatment efficacy [7-10]. HCQ blood levels can be quantified by high performance liquid chromatography coupled to several detectors such as mass spectrometry which is the most specific and sensitive detection [11-13]. 
The purpose of our work is to determine for the first time in Morocco, the blood concentrations of HCQ in SLE patients and identify the factors associated with interindividual variation in blood HCQ concentrations. Liquid chromatography coupled to tandem mass spectrometry was used for this determination.

\section{METHODS}

The study involved 80 Moroccan patients with SLE. All SLE patients were followed in the department of Internal Medicine B, Mohammed V Military Teaching Hospital of Rabat, Morocco, and fulfilled at least four of eleven criteria for SLE classification [14]. All patients were treated with HCQ prescribed at a stable oral dose of $400 \mathrm{mg}$ /day (200 mg twice a day) for at least 6 months. The main exclusion criteria include: pregnancy, renal failure and any patient refusing to participate in the study. The samples from all patients were taken at the same time of the day. This study was conducted according to the principles of the declaration of Helsinki and was approved by the local Ethical Committee from the Faculty of Medicine and Pharmacy, Rabat, Morocco.

For HCQ assays, blood was collected in EDTA vacutainers tube. HCQ was quantified by Acquity ultraperformance liquid chromatography coupled to a Tandem mass spectrometer (ACQUITY UPLC-TQD, Waters) in multiple reactions monitoring mode.

In a $5 \mathrm{~mL}$ test glass tubes, $20 \mu \mathrm{L}$ of internal standard solution at $1 \mathrm{mg} / \mathrm{L}$ (Milnacipran; Merck) and $100 \mu \mathrm{l}$ of $5 \%$ ammonia solution were added to $200 \mu \mathrm{L}$ of blood, calibrator or control and then vortexed for 1 min. Organic extraction was carried out by adding $2 \mathrm{~mL}$ of Dichloromethane/Ether (4/6), with vortexing for 1 min, then centrifuging the mixture for $5 \mathrm{~min}$ at 4000 $\mathrm{rpm}$. The organic layer was subsequently removed and placed in maximum recovery vials (Waters Corporation, Milford, MA, USA) and dried under a stream of nitrogen at $50{ }^{\circ} \mathrm{C}$. The samples were then reconstituted in $200 \mathrm{~mL}$ of mobile phase, and $5 \mu \mathrm{L}$ was injected into an ACQUITY UPLC-TQD, giving an injection-to-injection time of $4 \mathrm{~min}$. The mass spectrometer conditions were: capillary voltage, $1.1 \mathrm{kV}$; cone voltage, $40 \mathrm{~V}$; desolvation temperature, $450{ }^{\circ} \mathrm{C}$; desolvation gas, $800 \mathrm{~L} / \mathrm{h}$; source temperature, $120{ }^{\circ} \mathrm{C}$; and collision gas flow, 5.1 $10^{-3}$ mbar. The instrument was operated in positive electrospray ionization mode using MassLynxTM 4.1 software, with auto data processing by TargetLynxTM Application Manager (Waters Corp). Chromatographic separations were achieved using a BEH C18 UPLC column (1.7 $\mu \mathrm{m}, 2.1$ - $50 \mathrm{~mm}$; Waters Corp). Mobile phase a comprised acetonitrile, and phase B consisted of $2 \mathrm{mM}$ ammonium formate with $0.1 \%$ formic acid in water; the flow rate in all steps was $0.6 \mathrm{~mL} / \mathrm{min}$ in a gradient program. For each analytical run, calibrators and quality control samples were freshly prepared.

For statistical analysis the patients were divided according to their blood level. Levels less than $500 \mathrm{ng} / \mathrm{mL}$ were considered to have a low blood HCQ concentration, levels between 500 and $2000 \mathrm{ng} / \mathrm{mL}$ were therapeutic to have a therapeutic range and greater than $2000 \mathrm{ng} / \mathrm{mL}$ were considered high blood HCQ concentration. Statistical analysis was performed with SPSS 13.0 for windows (SPSS, Inc., Chicago, IL, USA). Depending on their normal or skewed distribution, data are reported as mean \pm standard deviation (SD) or median and full range and qualitative data as absolute numbers and percentage. Comparison between variables was performed using ANOVA test or the chi square test. The level of significance was set as $\mathrm{p}<0.05$ for all analyses.

\section{RESULTS AND DISCUSSION}

The determination of blood HCQ levels was carried out by liquid chromatography tandem mass spectrometry (Figure 1). The method was validated and found to be linear across the wide range of 20-2000 $\mathrm{ng} / \mathrm{mL}$. The limit of detection (LOD) and limit of quantification (LOQ) were $5 \mathrm{ng} / \mathrm{mL}$ and $20 \mathrm{ng} / \mathrm{mL}$, respectively.

The demographics data of the group are outlined in Table 1 . The analysis included 80 patients, they were for the most part female $(n=77,96 \%)$. Their mean age was $36.9 \pm 12,2$ years. The median concentration of HCQ was $830 \mathrm{ng} / \mathrm{mL}$ (range: $35-3,200$ $\mathrm{ng} / \mathrm{mL}$ ). The distribution of these concentrations was as follows: 13 patients $(16 \%)$ had low blood levels $(<500$ $\mathrm{ng} / \mathrm{mL}$ ), of these, 6 had levels of HCQ in their blood $<200 \mathrm{ng} / \mathrm{mL} ; 59$ patients $(74 \%)$ were in therapeutic range while $8(10 \%)$ patients had high blood HCQ concentrations (>2000 ng/mL) (Table 2).

There was a statistically significant difference seen when the body mass index (BMI) was compared with respect to the proportion in each hydroxychloroquine group; low BMI seems to be associated to high HCQ blood levels ( $\mathrm{p}=0.03)$. Cutaneous disorder, mucosal ulcers, arthritis, serositis, neuropsychatric disorder, anemia, lymphopenia, anti double stranded deoxyribose nucleic acid antibodies, anti-Smith antibodies and antinuclear antibodies did not distinguish any differences in hydroxychloroquine level. However, the use of corticosteroids appears to increase this blood concentration $(\mathrm{p}=0.02)$ (Table 2).

HCQ is a cornerstone in medical management of SLE with its affordable price and relative safety. In chronically treated patients, monitoring of HCQ concentrations helps clinicians in identifying adherence and prevents side effects which contributes to the success of the treatment [15]. In our study we measured 
HCQ blood levels for 80 SLE patients with liquid chromatography-tandem mass spectrometry.

The median concentration of HCQ was 830 $\mathrm{ng} / \mathrm{mL}$ with extremes between 35 and $3200 \mathrm{ng} / \mathrm{mL}$.

It is obviously difficult to compare our result with those of other studies because of the difference in sample size, ethnicities and the diversity of therapeutic protocols. For example, Jallouli et al. report a median concentration of $917 \mathrm{ng} / \mathrm{mL}$ (range 208-3,316 ng/mL) for 509 patients [16]. In another study, Miceli et al. found a median level of $722 \mathrm{ng} / \mathrm{mL}$ (range 0-2466 $\mathrm{ng} / \mathrm{mL}$ ) for 55 patients [17]. The optimal blood level of HCQ to achieve efficacy in SLE is still a subject of controversy. It has been reported that low HCQ blood levels are associated with higher SLE disease activity; while HCQ levels above $1000 \mathrm{ng} / \mathrm{mL}$ tend to improve the course of the disease [7]. However, this level is often difficult to maintain.

Among our patients, 6 had levels of blood HCQ below $200 \mathrm{ng} / \mathrm{mL}$; these patients were clearly nonadherent even if they declared apply the treatment properly. The cut-off of $200 \mathrm{ng} / \mathrm{mL}$ was suggested by further studies to distinguish nonadherent patients [16]. Non-adherence to medication and/or low blood HCQ levels are associates with poor outcomes and disease flare $[18,19]$.

Several factors could influence the blood level of HCQ. In addition to adherence to treatment, gender and therapeutic protocol may be factors in varying this concentration. For the same daily dose, the blood concentration of HCQ may be higher in women than in men [16]. This result was not verified in our study because of the small proportion of men compared to women.
The treatment schedule may influence the blood levels of HCQ; even if the optimal daily dose of HCQ in SLE is a subject of controversy, it has been found that patients receiving $400 \mathrm{mg}$ once a day have higher blood HCQ concentration than those receiving $200 \mathrm{mg}$ twice a day [16]. In our study, all patients receive $200 \mathrm{mg}$ twice a day. Taking $400 \mathrm{mg}$ of HCQ once a day may be more convenient for patients and help with treatment success and improvement of adherence.

Low BMI was found to be associated to high HCQ concentration $(\mathrm{p}=0.03)$. This finding could be explained by the large volume of distribution of HCQ; therefore, therapeutic monitoring of HQC could be particularly useful in patients with low BMI. This result has been found in other studies [16, 20, 21] and low body weight was previously found to be a risk factor for HCQ toxicity particularly ophthalmic [20, 21].

Treatment with corticosteroids seems to increase the blood concentration of HCQ $(p=0.02)$. This result has been reported by a previous study; this may be due to a potentiating effect as suggested by Jallouli et al. but it remains a theory [16]. The same study reports that low platelet and neutrophil were associated to low blood HCQ concentration [16]; this founding was not revealed by our results.

This study is, to the best of our knowledge, the first of its kind in Morocco; however, the relatively small sample size was one of our limitations in this study; we suggest that multicenter approaches may be necessary to attain larger sample size.

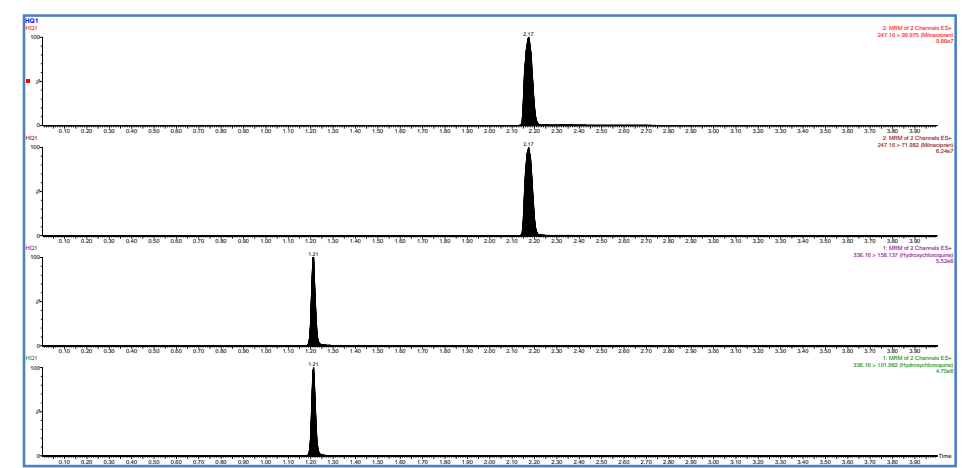

Fig-1: Chromatogram of Hydroxychloroquine (MRM transitions $\mathrm{m} / \mathbf{z} 336>158,336>102$, retention time 1.21 min) and Milnacipran as an internal standard (MRM transitions $\mathrm{m} / \mathrm{z} 247>72,247>158$, retention time $2.17 \mathrm{~min}$ )

Table-1: Characteristic and blood HCQ levels of SLE patients

\begin{tabular}{|l|c|}
\hline & SLE \\
\hline Number of subjects & 80 \\
\hline Female/male & $77 / 3$ \\
\hline Age (years) & $36.9 \pm 12.2$ \\
\hline Hydroxychloroquine (ng/mL) & $830(35-3200)$ \\
\hline
\end{tabular}


Table-2: Characteristics of patients with SLE, by blood HCQ concentrations

\begin{tabular}{|l|c|c|c|c|}
\hline & $\begin{array}{c}\text { Low blood HCQ } \\
\text { concentration } \\
(\mathbf{n = 1 3 , 1 6 \% )}\end{array}$ & $\begin{array}{c}\text { Therapeutic } \\
\text { range } \\
(\mathbf{n = 5 9 , 7 4 \% )}\end{array}$ & $\begin{array}{c}\text { High blood HCQ } \\
\text { concentration } \\
(\mathbf{n = 8 , ~ 1 0 \% )}\end{array}$ & P \\
\hline Age (years) & $36.7 \pm 13.1$ & $37.0 \pm 12.6$ & $37.1 \pm 13.8$ & 0.51 \\
\hline BMI (kg/m $\left.{ }^{2}\right)$ & $24.9 \pm 3.2$ & $23.7 \pm 1.9$ & $23.1 \pm 2.3$ & 0,03 \\
\hline Cutaneous disorder (68/80) & $10(15 \%)$ & $51(75 \%)$ & $7(10 \%)$ & 0.43 \\
\hline Mucosal ulcers (10/80) & $3(30 \%)$ & $6(60 \%)$ & $1(10 \%)$ & 0.35 \\
\hline Arthritis (77/80) & $11(14.3 \%)$ & $60(77.9 \%)$ & $6(7.8 \%)$ & 0.54 \\
\hline Serositis (20/80) & $6(30 \%)$ & $12(60 \%)$ & $2(10 \%)$ & 0.52 \\
\hline Neuropsychiatric disorder (22/80) & $4(18 \%)$ & $16(73 \%)$ & $2(9 \%)$ & 0.16 \\
\hline Anaemia (24/80) & $3(12.5 \%)$ & $20(83.3 \%)$ & $1(4.2 \%)$ & 0.16 \\
\hline Thrombocytopenia (20/80) & $4(20 \%)$ & $10(50 \%)$ & $6(30 \%)$ & 0.06 \\
\hline Leukopenia (26/80) & $4(15.4 \%)$ & $21(80.8 \%)$ & $1(3.8 \%)$ & 0.15 \\
\hline Lymphopenia (30/80) & $5(16.7 \%)$ & $22(66.6 \%)$ & $5(16.7 \%)$ & 0.31 \\
\hline Anti-dsDNA (57/80) & $9(15.8 \%)$ & $44(77.2 \%)$ & $4(7 \%)$ & 0.58 \\
\hline Anti-Sm (13/80) & $2(15.4 \%)$ & $10(76.9 \%)$ & $1(7.7 \%)$ & 0.68 \\
\hline ANA presence (71/80) & $12(16.9 \%)$ & $53(74.7 \%)$ & $6(8.4 \%)$ & 0.53 \\
\hline Use of corticosteroids (53/80) & $3(5.7 \%)$ & $42(79.2 \%)$ & $8(15.1 \%)$ & 0,03 \\
\hline
\end{tabular}

ANA: Antinuclear antibodies; dsDNA: double stranded deoxyribose nucleic acid; Sm: Smith

\section{CONCLUSION}

We reported for the first time a determination of HCQ blood levels in SLE Moroccan patients. Monitoring HCQ blood levels is considered as an important tool to improve medication adherence in patients with SLE and prevent side effects. Unfortunately, this assay cannot be generalized in the Moroccan laboratory for lack of the necessary equipment, in particular the liquid chromatography tandem mass spectrometry.

\section{REFERENCES}

1. Aouhab, Z., Hong, H., Felicelli, C., Tarplin, S., \& Ostrowski, R. A. (2019). Outcomes of Systemic Lupus Erythematosus in Patients who Discontinue Hydroxychloroquine. ACR open rheumatology.

2. Canadian Hydroxychloroquine Study Group*. (1991). A randomized study of the effect of withdrawing hydroxychloroquine sulfate in systemic lupus erythematosus. New England Journal of Medicine, 324(3), 150-154.

3. Ruiz-Irastorza G, Egurbide MV, Pijoan JI, Garmendia M, Villar I, Martinez-Berriotxoa A, Erdozain JG, Aguirre C. Effect of antimalarials on thrombosis and survival in patients with systemic lupus erythematosus. Lupus. 2006 Sep;15(9):57783.

4. Gerstein HC, Thorpe KE, Taylor DW, Haynes RB. The effectiveness of hydroxychloroquine in patients with type 2 diabetes mellitus who are refractory to sulfonylureas - a randomized trial. Diabetes research and clinical practice. 2002 Mar 1;55(3):209-19.

5. Cairoli E, Rebella M, Danese N, Garra V, Borba EF. Hydroxychloroquine reduces low-density lipoprotein cholesterol levels in systemic lupus erythematosus: a longitudinal evaluation of the lipid-lowering effect. Lupus.

2012

Oct;21(11):1178-82.

6. Ponticelli C, Moroni G. Hydroxychloroquine in systemic lupus erythematosus (SLE). Expert opinion on drug safety. 2017 Mar 4;16(3):411-9.

7. Costedoat-Chalumeau N, Galicier L, Aumaître O, Francès C, Le Guern V, Lioté F, Smail A, Limal N, Perard L, Desmurs-Clavel H, Asli B. Hydroxychloroquine in systemic lupus erythematosus: results of a French multicentre controlled trial (PLUS Study). Annals of the rheumatic diseases. 2013 Nov 1;72(11):1786-92.

8. Munster, T., Gibbs, J. P., Shen, D., Baethge, B. A., Botstein, G. R., Caldwell, J., ... \& McLaughlin, G. E. (2002). Hydroxychloroquine concentrationresponse relationships in patients with rheumatoid arthritis. Arthritis \& Rheumatism: Official Journal of the American College of Rheumatology, 46(6), 1460-1469.

9. Francès, C., Cosnes, A., Duhaut, P., Zahr, N., Soutou, B., Ingen-Housz-Oro, S., ... \& CostedoatChalumeau, N. (2012). Low blood concentration of hydroxychloroquine in patients with refractory cutaneous lupus erythematosus: a French multicenter prospective study. Archives of dermatology, 148(4), 479-484.

10. Costedoat- Chalumeau, N., Amoura, Z., Hulot, J. S., Hammoud, H. A., Aymard, G., Cacoub, P., ... \& Musset, L. (2006). Low blood concentration of hydroxychloroquine is a marker for and predictor of disease exacerbations in patients with systemic lupus erythematosus. Arthritis \& Rheumatism: Official Journal of the American College of Rheumatology, 54(10), 3284-3290.

11. Wang, L. Z., Ong, R. Y. L., Chin, T. M., Thuya, W. L., Wan, S. C., Wong, A. L. A., ... \& Goh, B. C. (2012). Method development and validation for rapid quantification of hydroxychloroquine in 
human blood using liquid chromatography-tandem mass spectrometry. Journal of pharmaceutical and biomedical analysis, 61, 86-92.

12. Füzéry, A. K., Breaud, A. R., Emezienna, N., Schools, S., \& Clarke, W. A. (2013). A rapid and reliable method for the quantitation of hydroxychloroquine in serum using turbulent flow liquid chromatography-tandem mass spectrometry. Clinica Chimica Acta, 421, 79-84.

13. Soichot, M., Mégarbane, B., Houzé, P., Chevillard, L., Fonsart, J., Baud, F. J., ... \& Bourgogne, E. (2014). Development, validation and clinical application of a LC-MS/MS method for the simultaneous quantification of hydroxychloroquine and its active metabolites in human whole blood. Journal of pharmaceutical and biomedical analysis, 100, 131-137.

14. Tan, E. M., Cohen, A. S., Fries, J. F., Masi, A. T., Mcshane, D. J., Rothfield, N. F., ... \& Winchester, R. J. (1982). The 1982 revised criteria for the classification of systemic lupus erythematosus. Arthritis \& Rheumatism: Official Journal of the American College of Rheumatology, 25(11), 1271-1277.

15. Geraldino-Pardilla, L., Perel-Winkler, A., Miceli, J., Neville, K., Danias, G., Nguyen, S., ... \& Askanase, A. (2019). Association between hydroxychloroquine levels and disease activity in a predominantly Hispanic systemic lupus erythematosus cohort. Lupus, 0961203319851558.

16. Jallouli, M., Galicier, L., Zahr, N., Aumaitre, O., Frances, C., Le Guern, V., ... \& Desmurs- Clavel, H. (2015). Determinants of hydroxychloroquine blood concentration variations in systemic lupus erythematosus. Arthritis \& rheumatology, 67(8), 2176-2184.

17. Miceli, J., Neville, K., Geraldino-Pardilla, L., \& Askanase, A. D. (2016, October). Hydroxychloroquine Blood Level Monitoring in a Predominantly Hispanic Systemic Lupus Erythematosus Cohort. In arthritis \& rheumatology (vol. 68). 111 river st, hoboken 07030-5774, nj usa: wiley.

18. Costedoat-Chalumeau, N., Amoura, Z., Hulot, J. S., Aymard, G., Leroux, G., Marra, D., ... \& Piette, J. C. (2007). Very low blood hydroxychloroquine concentration as an objective marker of poor adherence to treatment of systemic lupus erythematosus. Annals of the rheumatic diseases, 66(6), 821-824.

19. Bruce, I. N., Gladman, D. D., \& Urowitz, M. B. (2000). Factors associated with refractory renal disease in patients with systemic lupus erythematosus: the role of patient nonadherence. Arthritis Care \& Research, 13(6), 406-408.

20. Browning, D. J. (2013). Impact of the revised American Academy of Ophthalmology guidelines regarding hydroxychloroquine screening on actual practice. American journal of ophthalmology, 155(3), 418-428.

21. Marmor, M. F., Kellner, U., Lai, T. Y., Lyons, J. S., \& Mieler, W. F. (2011). Revised recommendations on screening for chloroquine and hydroxychloroquine retinopathy. Ophthalmology, 118(2), 415-422. 